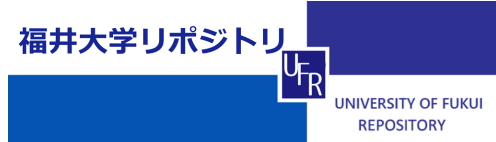

M cro- I ncrement al Forming of $\mathrm{Ti}$ and $\mathrm{Au}$ Foi I s by I ndent at i on Net hod

\begin{tabular}{|l|l|}
\hline 著者 & $\begin{array}{l}\text { OTSU Masaaki , TAN GUCH Hi roshi , TAKASH MA } \\
\text { Kazuki }\end{array}$ \\
\hline $\begin{array}{l}\text { j our nal or } \\
\text { publ i cat i on t i t l e }\end{array}$ & Key engi neer i ng mat er i al s \\
\hline vol une & $345-346$ \\
\hline page range & $1101-1104$ \\
\hline year & 2007 \\
\hline URL & ht t p: //hdl . handl e. net /10098/6395 \\
\hline
\end{tabular}




\title{
Micro-Incremental Forming of Ti Foils by Indentation Method
}

\author{
Masaaki Otsu, Hiroshi Taniguchi, Kazuki Takashima \\ Department of Materials Science and Engineering, Kumamoto University, Kumamoto 860-8555, Japan
}

Ti foils with a thickness of $10 \mu \mathrm{m}$ were formed by indenting at a place neighboring another indented place sequentially by means of a hemispherical diamond tool with a radius of $5 \mu \mathrm{m}$. In this forming method, forming dies are not necessary and commercial equipments for nanoindentation can be used. Forming load and pitch were changed in single line forming and forming direction, line pitch and line number were changed in plural line forming, and bending angle was investigated. From the experimental results, as the forming pitch increased, bending angle decreased. When the forming line pitch was changed, bending angle had the maximum peak at a pitch of $30 \mu \mathrm{m}$ by one-way forming path and $25 \mu \mathrm{m}$ by two-way forming path. Bending angle by one-way forming path was larger than that by two-way forming path. As forming line number increased, although bending angle increased, increment of them became smaller.

Keywords: titanium foil, bending, indentation method

\section{Introduction}

Recently, MEMS (Micro-Electro-Mechanical Systems) devices are promising technology for applications to such as precise devices, biomedical equipments, automotive parts and so on. Most parts consisting MEMS devices are manufactured by photolithography. Therefore it is possible to create three-dimensional shaped parts by means of layer by layer method with arranging two-dimensionally. It is, however, difficult to make three-dimensional shaped parts in any direction. If micro parts with three-dimensional shape for MEMS devices could be manufactured by forming plastically, micro devices having higher function and specification would be able to manufacture.

In general plastic working process, tools, dies and punches are employed. When the dies are used, the accuracy of formed shape depends on that of the dies and the accuracy of dies required severer than that of parts. So it becomes difficult to realize enough precision of dies as the parts size becomes smaller. Another problem in micro-plastic working is adjusting the positions of tool, dies and material. Since electric circuit and parts should be created in the same time, there are also many problems in using dies. Since most parts of MEMS devices are manufactured by integrating layers made by photolithography, the thickness of parts is much smaller than the length and width, and foil forming should be performed. Then the degree of spring back is very great because of its small thickness and it becomes very hard to control forming shape.

On the other hand, incremental forming process ${ }^{1)}$, which is one of die free forming method of metal sheets, employs only a simple tool for forming sheets. In this process, the tool is moved along the contour line of the destination shape and the sheet is formed by integrating local deformation. Since a simple shape tool is used, the problems such as making precise dies and tool interfering with parts connected electric circuit are eliminated. Although some researches about micro-incremental forming ${ }^{2-4)}$ have reported, the number of them is still small. For giving local deformation at very small area, nanoindentation test are performed very much. If making many indentations strategically by the nanoindenter, deformed shape of very small and thin parts should be controlled by using commercial nanoindentation machines

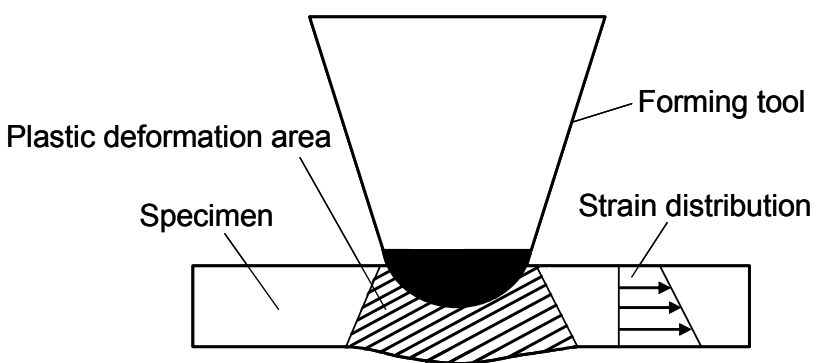

(a) Deformation model

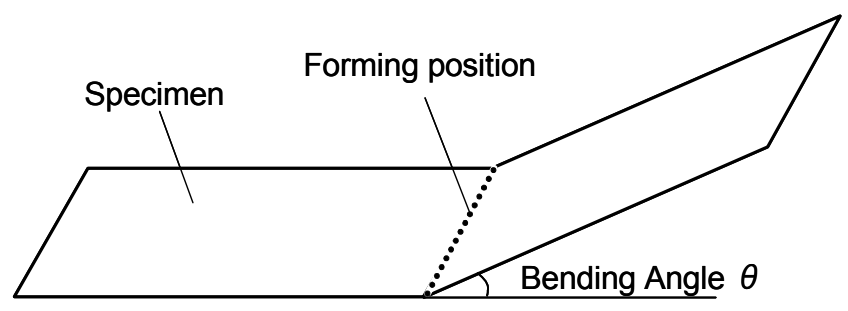

(b) Formed shape

Figure 1. Mechanism of micro-incremental forming by indentation method.

widely used without special equipments.

In this study, micro-incremental forming of metal foils by indentation method was carried out. Ti foils which are considered to be used for MEMS devices for biomedical equipments were employed for specimen. Effects of forming load, pitch and line number on bending angle were investigated.

\section{Experimental Method}

\subsection{Mechanism of Forming}

Mechanism of micro-incremental forming by indentation method can be explained by Figure 1. This is similar to shot peen forming ${ }^{5}$ applied to forming shell of air plane body and wings. When a specimen foil is pushed by a forming tool, the surface of the foil is slightly bent and deformed concavely and the material flows side way. Since strain of the bottom part of pushed area is greater than that of the surface area, the specimen is bent forward to the tool direction after removing the tool like Figure 1(a). When 
many indentations are made in narrow domain with affecting each other, the deformations are integrated and the whole of specimen are formed like Figure 1(b).

\subsection{Material}

In this study, pure Ti foils with a length of $7 \mathrm{~mm}$, width of $1 \mathrm{~mm}$ and thickness of $10 \mu \mathrm{m}$ were employed for specimen. Although they are cold rolled foils, no heat treatment was carried out.

\subsection{Experimental Apparatus}

An experimental apparatus for micro-incremental forming by indentation method are illustrated in Figure 2. A specimen foil was fixed to a tungsten carbide block by adhesive tape and magnets at the both ends, and the block was put on an X-Y stage. A hemispherical diamond tip having $5 \mu \mathrm{m}$ radius was attached to a piezo actuator through a load cell. Indentation was carried out by moving the piezo actuator. The maximum stroke and the resolution of the actuator are $38 \mu \mathrm{m}$ and $0.2 \mathrm{~nm}$, respectively. The maximum load of the load cell can measure is $2 \mathrm{~N}$.

\subsection{Experimental Procedure}

First, a specimen foil was fixed to a holder made of

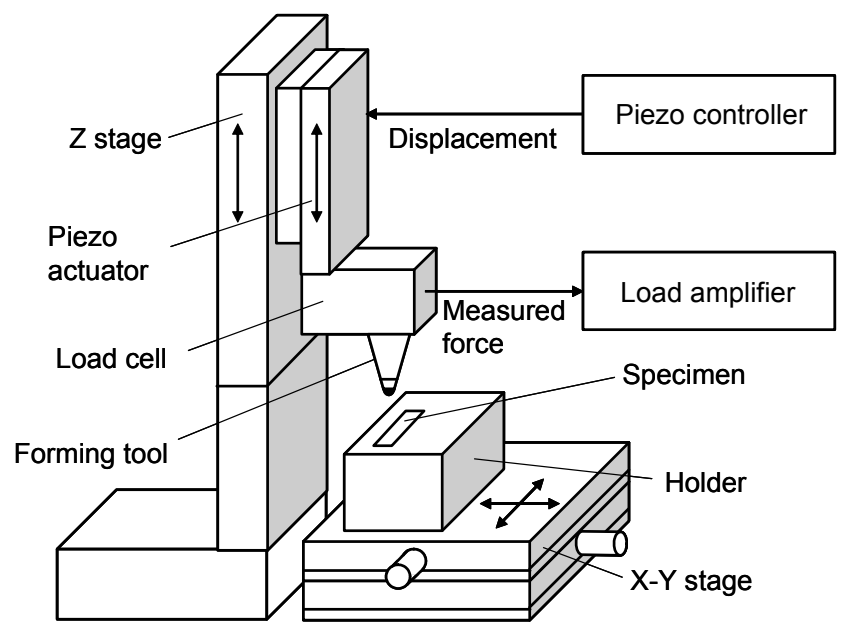

Figure 2. Experimental apparatus for micro-incremental forming by indentation method.

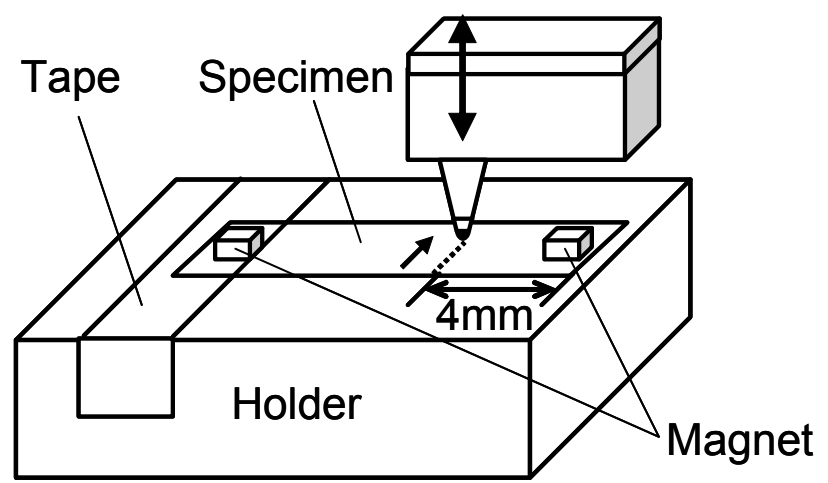

Figure 3. Forming method by micro-incremental forming tungsten carbide block by adhesive tape and magnet at the edge and the holder was put on a numerical control $\mathrm{X}-\mathrm{Y}$ stage. Then the initial shape of the foil was measured by a laser displacement sensor automatically using the NC X-Y stage. After measuring the shape, the other edge of specimen was fixed by a magnet and the holder was put on the X-Y stage of forming equipment. The piezo actuator and NC X-Y stage were moved with synchronizing each other and indentation process was carried out at the location of $4 \mathrm{~mm}$ from the edge as shown in Figure 3. Plural indentations were carried out linearly. Micro-incremental forming was performed by changing forming pitch, forming load, line pitch and line number. When plural line forming was performed, forming direction was also changed, one-way forming path and two-way forming path as shown in Figure 4. After forming, one magnet was removed and the holder was put on the NC X-Y stage of shape measuring equipment again and the formed shape was measured as well as the initial one.

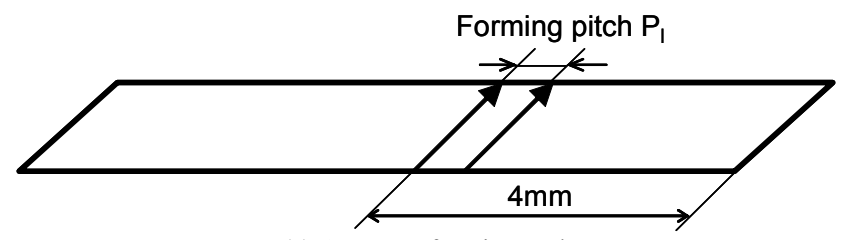

(a) One-way forming path

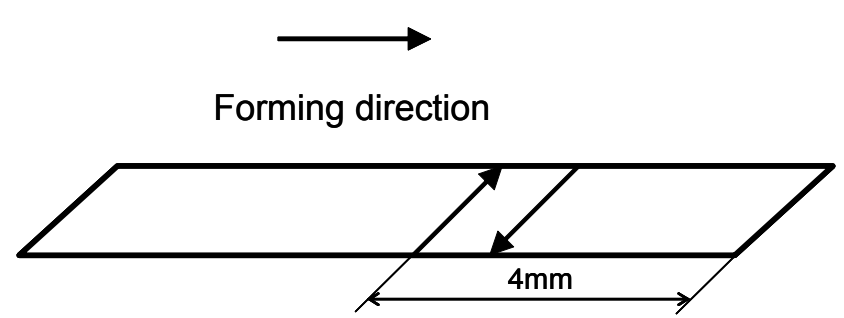

(b) Two-way forming path

Figure 4. Forming direction for plural line forming.

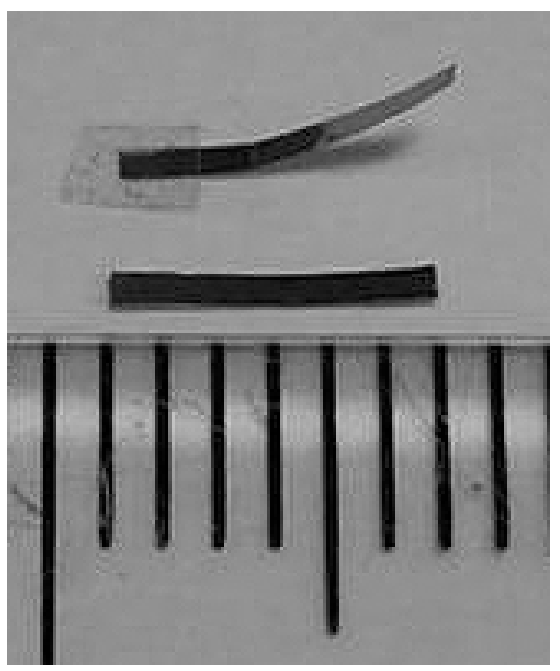

Figure 5. Appearance of micro-formed specimen. 


\section{Results and Discussions}

\subsection{Formed Shape}

Appearance of formed $\mathrm{Ti}$ foils is shown in Figure 5. Lower foil is the one before forming and upper is the one after forming. The specimen was bent at the indentation line. A photo of a cross section of bent foil when forming load is $F=0.21 \mathrm{~N}$ is shown in Figure 6 . The excluded volume by pushing with the hemispherical tool did not flow out of the foil surface and reverse side of the pushed place was expanded. This shape agrees well with mechanism of micro-incremental forming by indentation method as illustrated in Figure 1. The diameter of the indentation was $6.3 \mu \mathrm{m}$ and greater than that of the indenter. The reason of this is considered that when the indenter pushes the specimen, the tungsten carbide holder was deformed to concave shape elastically and the specimen fitted to the diamond tip shape and after unloading, the specimen was bent back elastically with the tungsten carbide holder.

\subsection{Single Line Forming}

Photos of formed surface of Ti foils are shown in Figure

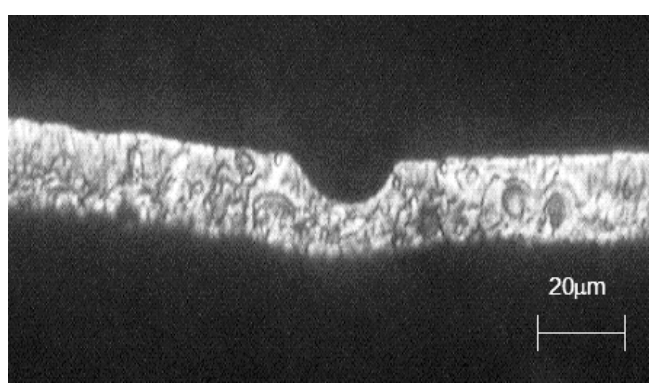

Figure 6. Cross section of formed Ti specimen. $(F=0.21 \mathrm{~N})$

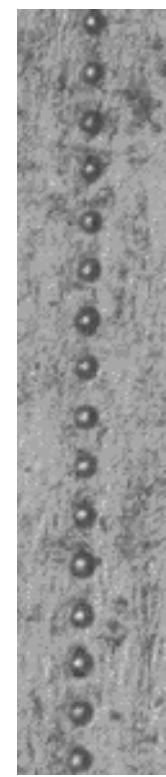

(a) $F=0.05 \mathrm{~N}$

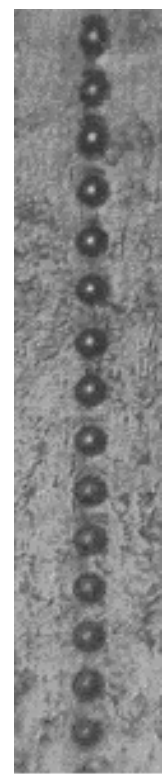

(b) $F=0.10 \mathrm{~N}$

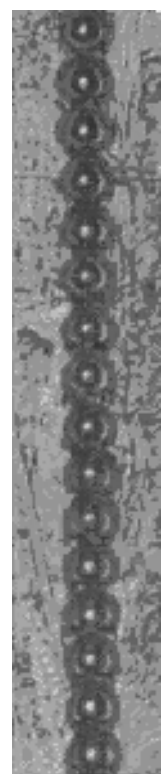

(c) $F=0.21 \mathrm{~N}$

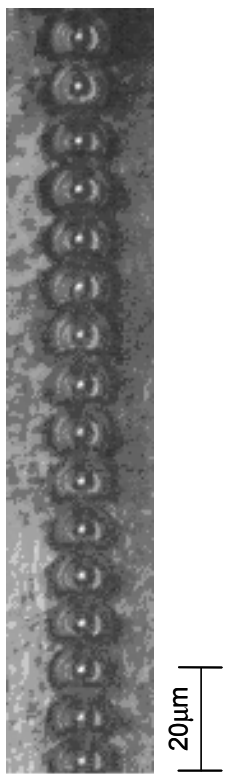

(d) $F=0.31 \mathrm{~N}$
7. The forming pitch was kept to $P=10 \mu \mathrm{m}$ and the forming load was changed in a range of $F=0.05-0.52 \mathrm{~N}$. Indentations align with same pitch and linearly.

Bending angle of $\mathrm{Ti}$ foils with keeping forming pith constant to $P=10 \mu \mathrm{m}$ and varying forming load in a range of $F=0.05-0.52 \mathrm{~N}$ is plotted in Figure 8 . As forming load increased, bending angle also increased. Increasing rate, however, became smaller when forming load exceeds $0.31 \mathrm{~N}$. This is because the indentations overlapped each other as shown in Figure 7.

Next, forming load was kept to $F=0.21 \mathrm{~N}$ and variation of bending angle when forming pitch was changed in a range of $P=5-20 \mu \mathrm{m}$ was investigated. The result is illustrated in Figure 9. Although bending angle was large when forming pitch was small, the degree of reduction of bending angle as forming pitch increased was small, and the effect of forming pitch on bending angle was small. When forming

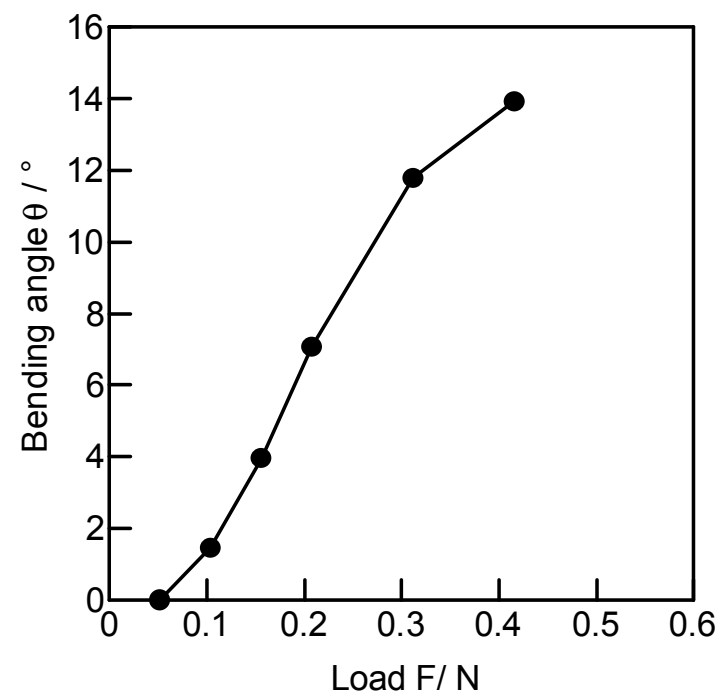

Figure 8. Relation between bending angle and forming depth. $(P=10 \mu \mathrm{m})$

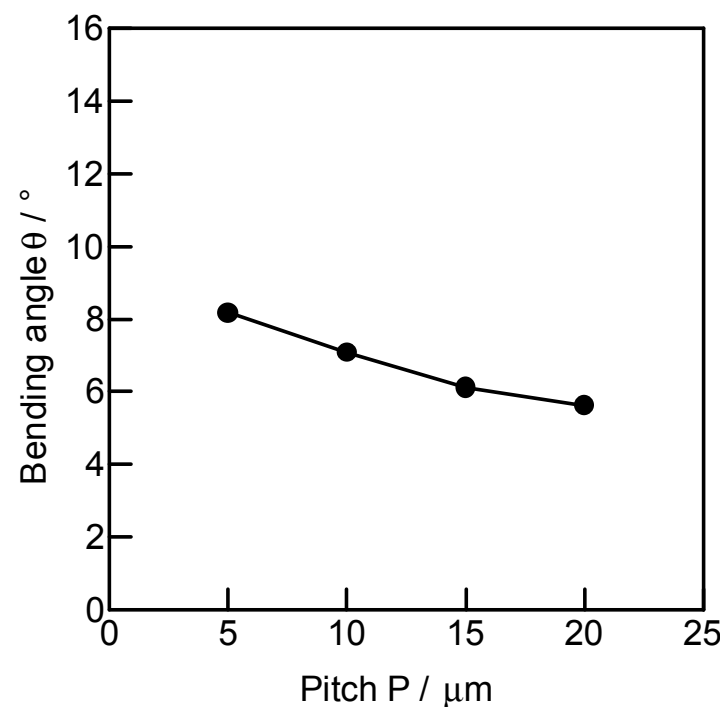

Figure 7. Indentation with changing forming load. 
pitch was $5 \mu \mathrm{m}$, the indentations overlapped each other. So considering from Figure 7 and Figure 8, bending angle will not become larger very much as forming pitch becomes smaller than $5 \mu \mathrm{m}$.

\subsection{Plural Line Forming}

Figure 10 shows the relationship between bending angle and forming line pitch. Forming pitch and forming load were kept constant to $P=10 \mu \mathrm{m}$ and $F=0.16 \mathrm{~N}$, respectively and forming line pitch, $P_{l}$, was changed from 7 to $40 \mu \mathrm{m}$. Results of both forming directions, one-way forming path and two-way forming path, were plotted. In both forming directions, bending angles had maximum peaks when forming line pitches were $25 \mu \mathrm{m}$ in case of two-way forming path and $30 \mu \mathrm{m}$ in case of one-way forming path, respectively and bending angle became small as forming line pitch increased. Comparing bending angle of both forming directions, that by one-way forming path was greater than that by two-way forming path.

Next, forming pitch, forming load and forming line pitch were fixed to $P=10 \mu \mathrm{m}, \quad F=0.16 \mathrm{~N}$ and $P_{l}=30 \mu \mathrm{m}$, respectively and $\mathrm{Ti}$ foils were formed by one-way forming path. Effect of forming line number on bending angle is expressed in Figure 11. As forming line number, $N$, increased, bending angle also increased. So bending angle is estimated to increase as forming line number increased. Increasing rates of $N=0-1$ and $1-2$ were almost equal and those of $N=2-3$ and 3-4 were also equal. Increasing rates of $N=1-2$ was, however, greater than that of $N=2-3$. This reason is considered as follows. When the second line is formed, the residual strain made in forming the first line is partially eliminated between the first and second lines. But the residual strain made in forming the second line is partially eliminated between the second and third lines. Therefore the residual strain between the first line and the second line becomes smaller than that outside of the first line and the third line, and increasing rate of bending angle of $N=2-3$ becomes smaller than that of $N=1-2$.

\section{Conclusions}

In this study, micro-incremental forming process using indentation method was proposed. Ti foils were bent by the proposed forming method. Effects of forming load, forming pitch, forming line pitch and forming line number on bending angle were investigated and following results were obtained.

(1) Although bending angle was greater as forming load increased, increasing rate became small when the indentations overlapped each other.

(2) When forming pitch was larger, bending angle became smaller, however, the effect of forming pitch on bending angle was not large.

(3) Bending angle had a maximum peak when forming line pitch was changed in plural line forming.

(4) Bending angle by one-way forming path was greater than that by two-way forming path.

(5) As forming line number increased, bending angle was also increased. Increasing rate of bending angle for $N=0-1$ and 1-2 was larger than that for $N=2-3$ and 3-4.

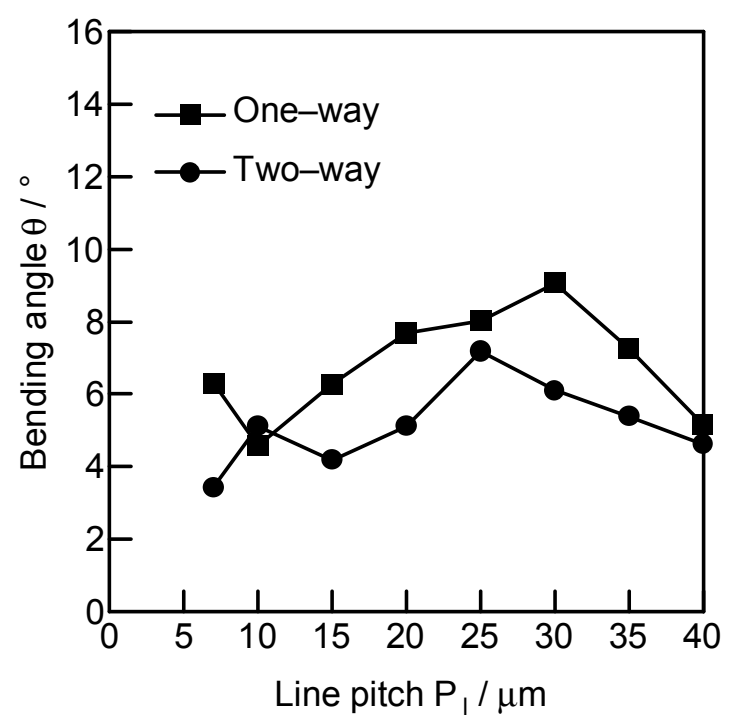

Figure 10. Relation between bending angle and forming line pitch in plural line forming. ( $F=0.16 \mathrm{~N}, P=10 \mu \mathrm{m})$

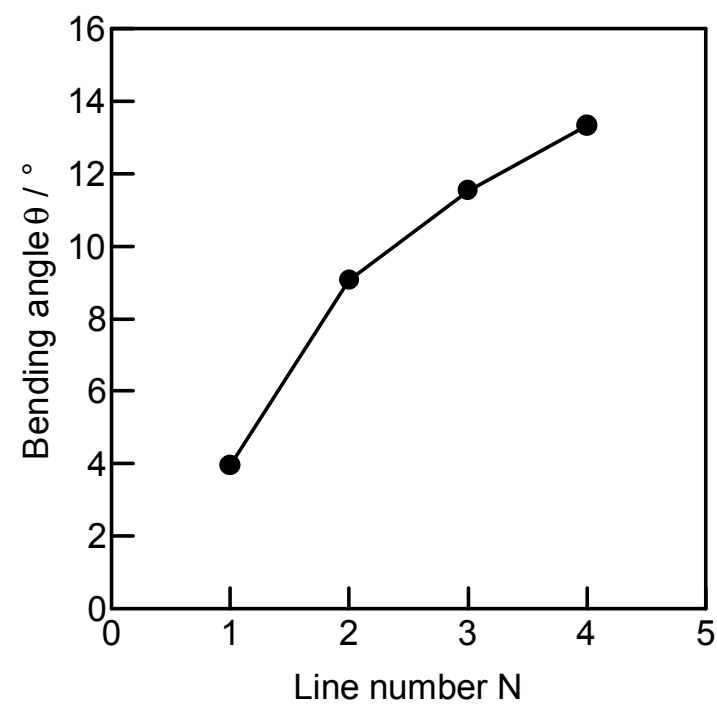

Figure 11. Effect of line number on bending angle. $(F=0.16 \mathrm{~N}, \quad P=10 \mu \mathrm{m}$, $\left.P_{l}=30 \mu \mathrm{m}\right)$

\section{REFERENCES}

1) M. Matsubara : J. Jpn. Soc. Technol. Plasticity, 35 (1994), pp. 1258-1263.

2) S. Tanaka and T. Nakamura : J. Jpn. Soc. Technol. Plasticity, 42 (2001), pp. 1020-1024.

3) Y. Saotome and T. Okamoto : J. Mater. Process. Technol. 113 (2001), pp. 636-640.

4) Y. Saotome, K. Yasuda and H. Kaga: J. Mater. Process. Technol. 113 (2001), pp. 641-647.

5) R. Kopp and J. Schulz : CIRP Annals Manuf. Technol., 51 (2002), pp. 195-198. 